Original papers

\title{
Integrated runoff and soil loss monitoring unit for small agricultural watersheds
}

\author{
Prabhakar Pathak ${ }^{\mathrm{a}, *}$, K. Chandrasekhar ${ }^{\mathrm{b}}$, Suhas P. Wani ${ }^{\mathrm{a}}$, Raghavendra Rao Sudi ${ }^{\mathrm{a}}$, Nagaraju Budama ${ }^{\mathrm{a}}$ \\ a ICRISAT Development Center, International Crops Research Institute for the Semi-Arid Tropics (ICRISAT), P.O. Patancheru, 502324 Hyderabad, India \\ ${ }^{\mathrm{b}}$ Farm and Engineering Services (Electronics Unit), ICRISAT, P.O. Patancheru, 502324 Hyderabad, India
}

\section{A R T I C L E I N F O}

\section{Article history:}

Received 4 November 2014

Received in revised form 10 August 2016

Accepted 12 August 2016

Available online 28 August 2016

\section{Keywords:}

Sediment flow behavior

Digital runoff recorder

Low cost sediment sampler

Efficient runoff sampling

Agricultural watershed

\begin{abstract}
A B S T R A C T
Runoff and sediment flow behaviors from small agricultural watersheds on Alfisols and Vertic Inceptisols, and their implications for the design of a runoff and soil loss monitoring unit are discussed. It was observed that a small segment of runoff hydrograph near peak discharge rate usually accounted for 65-85 percent of total storm soil loss. The runoff and sediment flow behavior recorded on the small agricultural watersheds indicated the need for an integrated digital runoff and soil loss monitoring unit (IDRSMU) to achieve higher accuracy and cost effectiveness. The design, development and testing of an IDRSMU to measure both the runoff and soil loss from small agricultural watersheds is presented. Under the field conditions its accuracy and efficiency for monitoring soil loss from small agricultural watersheds was observed good. Use of this integrated unit, makes the estimation of soil loss easy, rapid and accurate. The designed unit does smart runoff sampling by linking the runoff sampling intervals to the sediment load. This significantly reduces number of samples that needs to be collected, thereby reducing the operational cost, without compromising with the accuracy in estimating soil loss from small agricultural watersheds.
\end{abstract}

(c) 2016 Elsevier B.V. All rights reserved.

\section{Introduction}

High runoff and soil loss from agricultural fields are widespread and pose increasing threat to sustain agricultural productivity and environment in many parts of the developing world (Pagiola, 1999). This has led to many studies aimed at developing appropriate soil and water management practices and other technologies for controlling the degradation of soil and water resources and increasing agricultural productivity. Such studies invariably require rapid and accurate measurement of runoff and soil loss from the experimental areas. Runoff recorders and sediment samplers have been extensively used for measuring runoff and soil loss from the fields and watersheds (Davis, 2005; Dendy, 1973; Eads and Boolootian, 1985; Fasinmirin, 2009; Klik et al., 2004; Kornecki et al., 2008; Pathak, 1991; Wang et al., 1971). During the last decade digital runoff recorders for measuring runoff and microprocessor based runoff samplers for measuring soil loss have gained considerable acceptance over the mechanical type recorders because of their higher accuracy, reliability and operational efficiency (Black and Luce, 2013; Davis, 2005; Polyakov et al.,

\footnotetext{
* Corresponding author at: ICRISAT Development Center, Building No. 302, ICRISAT, Patancheru, 502324 Hyderabad, Telangana, India.

E-mail address: p.pathak@cgiar.org (P. Pathak).
}

2013; Sun et al., 2014; Zhao et al., 2001). Several new and innovative methods have been reported, however these are still need to be tested under field conditions (Zeng et al., 2014; Zhang et al., 2014). In most developing countries the collection of runoff samples for measuring soil loss is still done manually. This method of measuring soil loss is highly unreliable and inaccurate especially from small agricultural watersheds, which generally records very high time variation in sediment concentration during the runoff flow (Pathak et al., 2004). Some of the key reasons for still using manual sampling are the high cost of microprocessor-based samplers including operational costs and often they are not suitable for small agricultural watersheds. In addition, most of the available equipment's for monitoring runoff and soil loss from small agricultural watersheds either monitor runoff or soil loss, but not the both (Douglas, 2001). An integrated unit which monitors both runoff and soil loss could substantially reduce the cost of the equipment as well as may provide higher accuracy and operational efficiency. The purpose of our study was to develop efficient and cost effective microprocessor based integrated runoff and soil loss monitoring unit for small agricultural watersheds.

This paper presents the sediment flow behavior from small agricultural watersheds and its implications for the design and development of an integrated runoff and soil loss monitoring unit. The design and development of a low cost integrated runoff and soil 
loss monitoring unit that can do smart runoff sampling from small agricultural watersheds is presented. The field test performance in terms of accuracy, operational efficiency and cost effectiveness and other key features of this integrated unit are discussed.

\section{Materials and methods}

\subsection{Experimental sites}

The runoff and soil loss were measured in two small agricultural watersheds, one on a Vertic Inceptisol (BW7A) and another on an Alfisol (RW2) at the International Crops Research Institute for the Semi-Arid Tropics (ICRISAT) center in Patancheru, Hyderabad, India $\left(17^{\circ} 36^{\prime} \mathrm{N}, 78^{\circ} 16^{\prime} \mathrm{E}, 545 \mathrm{~m}\right.$ altitude). Salient characteristics of the watersheds are given in Table 1. In both the watersheds, we used the broad-bed and furrow system of land and water management along with improved crop production technologies.

The mean annual rainfall at the watershed sites is about $892 \mathrm{~mm}$. Rainfall is variable spatially and temporally, and often occurs in high intensity storms. During measurements of runoff and soil loss (2002-2012), the annual rainfall ranged from $535 \mathrm{~mm}$ to $1206 \mathrm{~mm}$ with a coefficient of variation of $24.1 \%$.

The Vertic Inceptisol at the experimental watershed is a medium deep black soil with mostly fine montmorillonitic clay (Virmani et al., 1991). The soil is self-mulching and exhibits cracking and swelling; and becomes hard when dry and sticky when wet. Because of 2:1 clay type and relatively high clay content, the soils have very low saturated hydraulic conductivity. Under dry conditions, these soils develop deep and wide cracks, reflecting substantial shrinkage. These cracks greatly influence the infiltration and runoff behavior of these soils particularly during the early periods of the rainy season. The Alfisol at the experimental watershed is a medium deep red soils; and belong to the fine, kaolinitic, isohyperthermic member of the family of Udic Rhodustalfs (El-Swaify et al., 1985). The soil has very low water retention characteristics and unstable structure mainly due to low contents of fine (clay-sized) particles and inactivity of the prevailing clay minerals (mostly kaolin). A major consequence of the lack or non-stability of aggregation is the tendency of these soils to display rapid surface sealing following rainfall and crusting with subsequent drying. This characteristic greatly influences the infiltration, runoff and soil loss behavior of these soils (Pathak et al., 2013).

\subsection{Data collection and analysis}

In both the watersheds, surface runoff was measured by using hydraulic structures and water-stage-level recorders (Thalimedes digital runoff recorder). In this recorder, the sampling and logging intervals of stage was set to 1 and 5 min intervals, respectively. The stage vs. time graph was subsequently processed to obtain the runoff rates and volume.

For measuring soil loss, runoff samples from all runoff events were collected using a microprocessor based runoff samplers in both watersheds. The runoff sampler collected and stored the runoff samples in separate containers at 10-min interval throughout the runoff events. These samples were analyzed in laboratory for sediment concentration in the runoff water. The concentration values were used to prepare sediment concentration vs. time graph, which was superimposed on the runoff hydrograph. Each runoff event hydrograph was divided into 10-min time segments. For each hydrograph segment, the soil loss was computed by multiplying the segment runoff volume with sediment concentration. The total soil loss for a runoff event was determined by adding the segment values.

During the field testing period (2010-2012) of IDRSMU, the observations on runoff and soil loss were made in the watersheds by using above mentioned equipment's as well as IDRSMU unit to compare their performance.

\section{Results and discussion}

\subsection{Sediment flow behavior from small agricultural watersheds and implications for the design of runoff and soil loss monitoring unit}

High variation in sediment concentration was recorded during the runoff events from the watersheds (Fig. 1). The Alfisol has a very coarse soil texture ( $13 \%$ clay, $9 \%$ silt and $78 \%$ sand) as compared to the fine textured Vertic Inceptisol (53\% clay, 22\% silt and $25 \%$ sand). The sediment flow characteristics of these two texturally contrasting soils are slightly different although the overall sediment flow pattern is similar. Compared to the Vertic Inceptisol, the sediment concentration was better with runoff discharge rates in the Alfisol watershed (Fig. 1). This is primarily because on Alfisol watershed most of the eroded sediments are coarse soil particles that are heavier and require greater flow energy for their transportation compared to mostly finer eroded soil particles from the Vertic Inceptisol watershed. This is supported by the trends in results shown in Fig. 2, which provide the relationships between the runoff discharge rate and sediment concentration recorded for the Alfisol and Vertic Inceptisol watersheds. During low runoff discharge rate, the sediment concentrations from the Alfisol watersheds was lower compared to those from the Vertic Inceptisol watershed. However, as the discharge rate increased, the sediment concentration from the Alfisol watershed is higher than those recorded from in the Vertic Inceptisol watershed. In addition, the results in Fig. 2 clearly show that there is close correlation between the runoff discharge rate and sediment concentration. As the runoff discharge rate increases the sediment concentration values also increases. This is true for both soils as well as for different types of runoff events. The relative importance of different segments of runoff hydrographs to total storm soil loss is shown in Fig. 3. The values shown in Fig. 3 are the mean values of all the runoff events recorded from watersheds during 2002-2010. The Figure shows that the runoff hydrograph segments viz. A, B \& C are important as these segments accounts for about $78 \%$ of the total storm soil loss. It must be noted that during these runoff hydrograph segments the discharge rates are also higher. However, in terms of time scale these three runoff - hydrograph segments accounts only about $15 \%$ of the total runoff duration. In other words during a small period of only $15 \%$, more than $78 \%$ of storm soil loss is recorded during a runoff event. It highlights the importance of these few runoff hydrograph segments for soil loss monitoring. These key findings from the sediment flow characteristics from the small agricultural watersheds (Figs. 1-3) are important for

Table 1

Brief description of Alfisol and Vertic Inceptisol watersheds at the ICRISAT research center, Patancheru, India.

\begin{tabular}{|c|c|c|c|c|c|}
\hline Soil type & $\begin{array}{l}\text { Watershed } \\
\text { name }\end{array}$ & $\begin{array}{l}\text { Area } \\
\text { (ha) }\end{array}$ & $\begin{array}{l}\text { Slope } \\
(\%)\end{array}$ & Land and water management system & Crops and cropping system \\
\hline Vertic Inceptisols & BW7A & 3.41 & 2.15 & Broadbed and furrow system at $0.6 \%$ slope with grassed waterways & Soybean/Chick pea/Maize/Safflower \\
\hline Alfisols & RW2 & 2.80 & 2.10 & Broadbed and furrow system at $0.6 \%$ slope with grassed waterways & Sorghum intercrop with Pigeonpea, and castor \\
\hline
\end{tabular}



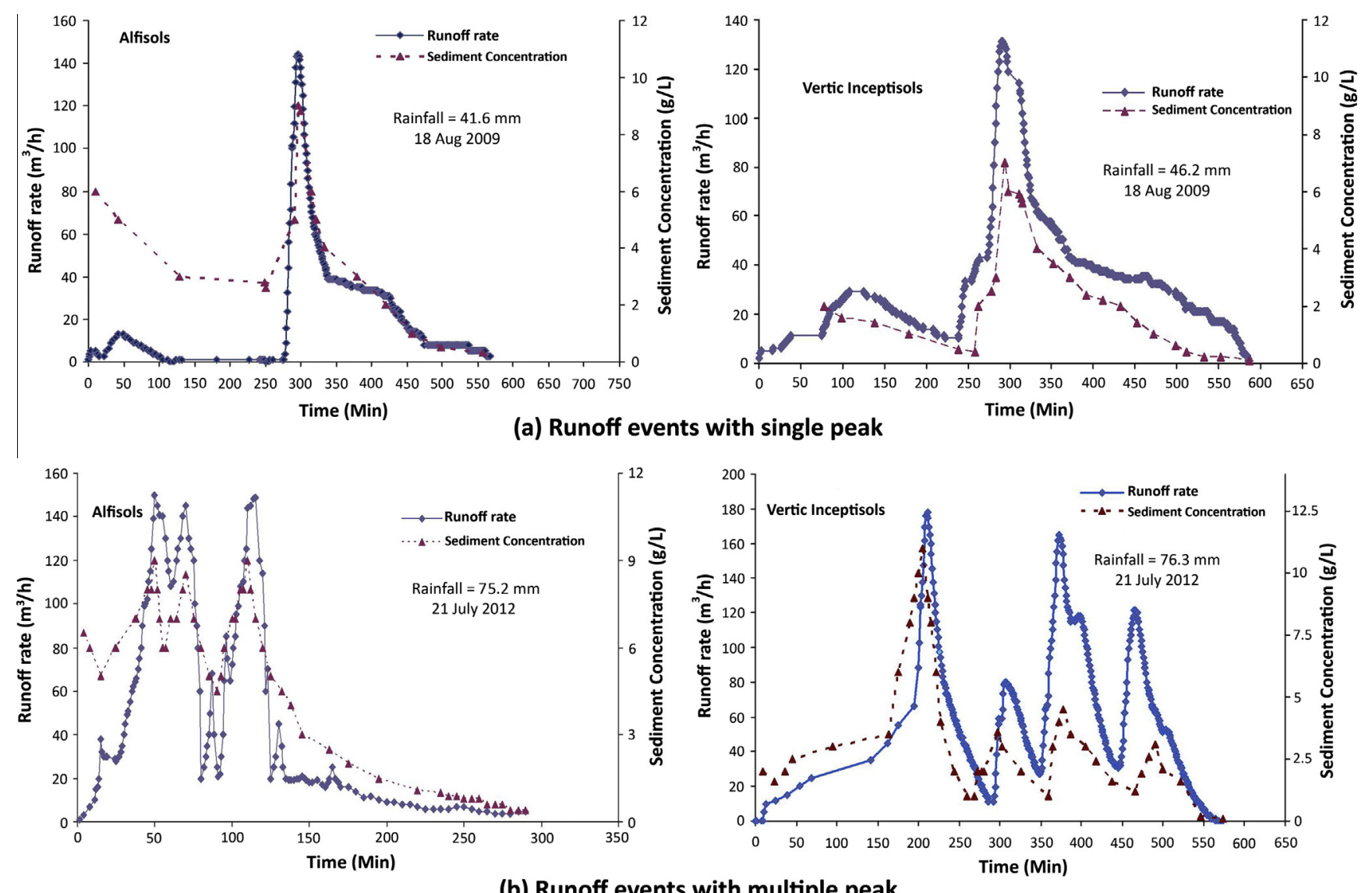

(b) Runoff events with multiple peak

Fig. 1. Variation in sediment concentration during different types of runoff events from small agricultural watersheds at the ICRISAT research center, Patancheru, India.

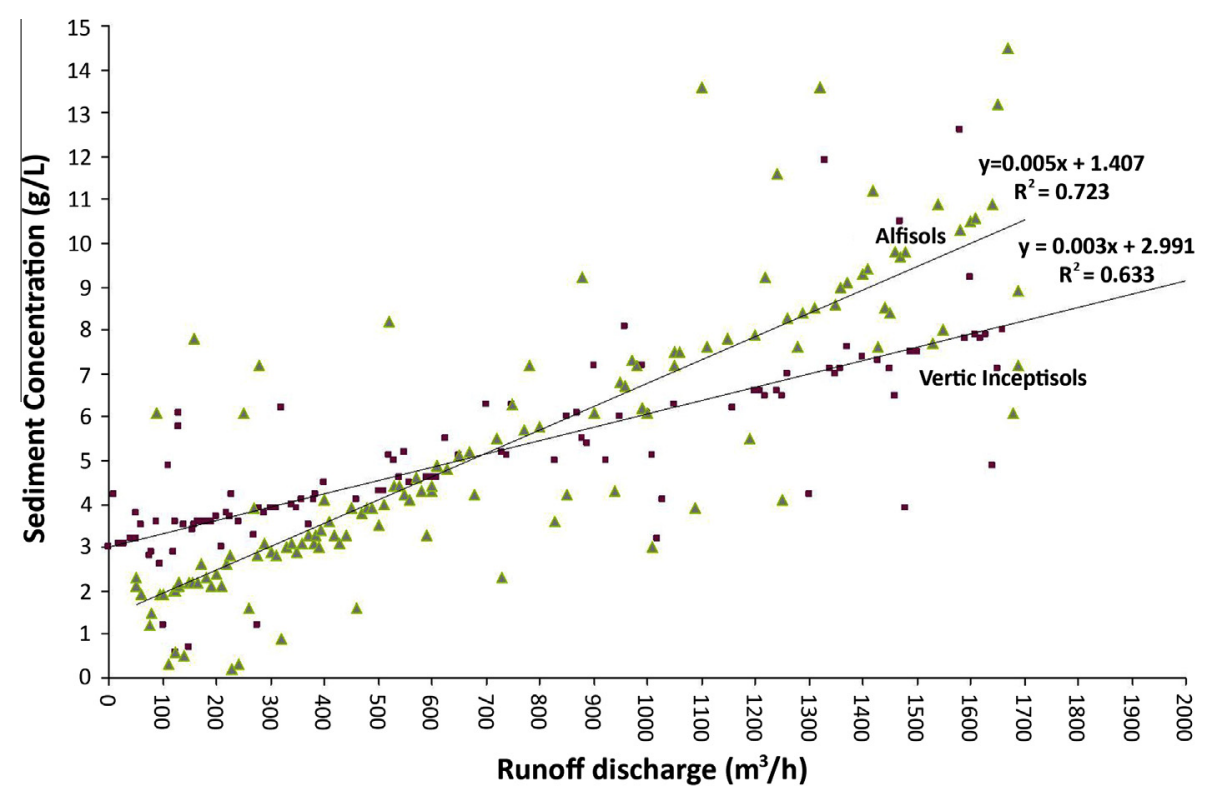

Fig. 2. Relationship between sediment concentration and runoff rate for two small agricultural watersheds at the ICRISAT research center, Patacheru, India (2002-2010).

the design and development of an efficient soil loss monitoring unit, which can be summarized as follows

- Extremely high variation in sediment concentration during runoff events. It means that the soil loss monitoring unit must collect the runoff samples throughout the runoff duration.
- There is direct correlation between the runoff discharge rate and sediment load/concentration. Higher the runoff discharge rate, higher is the sediment concentration as well as sediment load. During most runoff events only few hydrograph segments with higher runoff discharge rates account about $78 \%$ of the total storm soil loss, although these hydrograph segments 


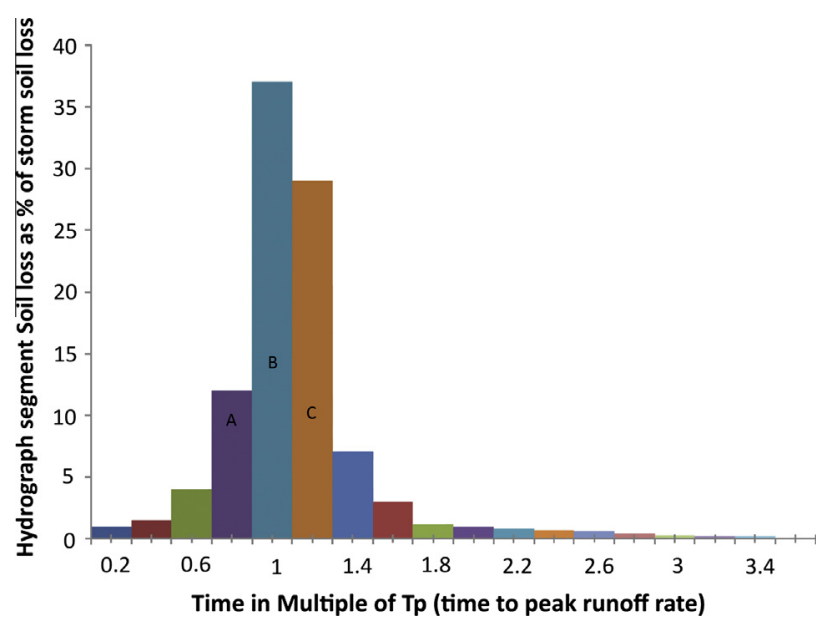

Fig. 3. Soil loss during different runoff hydrograph segments from an Alfisol watershed at the ICRISAT research center (2002-2010).

accounts only small percentage of total runoff time. Therefore, the soil loss monitoring unit must be designed to monitor more efficiently the sediment load particularly during these high discharge hydrograph segments. This can be achieved only by more frequently runoff sampling during high discharge periods compare to low discharge runoff periods. It can be best achieved by linking the runoff-sampling intervals with runoff discharge rates. This can be done only in integrated digital runoff and soil loss monitoring unit. In the integrated unit, the runoff sampling intervals can be programmed based on the discharge rates, to achieve higher accuracy in estimating soil loss and without collecting too many runoff samples mostly from the low discharge periods, which accounts very little to total storm soil loss. The design, development and performance of an integrated digital runoff and soil loss monitoring unit for small agricultural watersheds is discussed below.

\subsection{Integrated digital runoff and soil loss monitoring unit}

The developed integrated digital runoff and soil loss monitoring unit (IDRSMU) can be used to measure the runoff and soil loss from the agricultural fields and small watersheds. Although, this unit does not directly measures soil loss, but it collects runoff samples, which can be used for estimating soil loss. Since it is an integrated unit, the analysis of the soil loss is much faster and more accurate. The biggest advantage of this integrated unit is that the runoff sampling for estimating soil loss can be linked to either time scale or runoff flow characteristics; and this makes this unit highly effectiveness in collecting runoff samples at right time and intervals. Moreover, the unit can be used to measure any other open channel water flow viz. water flow in irrigation cannel. The entire runoff and sediment sampling operations are automatic and controlled by the data logger cum microprocessor control unit (DLCMCU). Besides the soil loss, the runoff samples collected by the unit can be used for estimating nutrients, pesticides or any other chemicals flow from the agricultural fields or small watersheds. The unit is highly suitable for studies that require more detailed information not only on the total soil loss, but on also temporal fluctuations in sediment/nutrient/pesticides movements during runoff event.

\subsubsection{Runoff recording}

The data logger cum microprocessor control unit (DLCMCU) of IDRSMU continuously measures the runoff water levels in the channel/drains through a float-operated shaft encoder along with data logger (Fig. 4). Changes in the water level are transferred via a float cable counter weight system to the float pulley on the encoder unit. The rotation caused by this action is converted to an electrical signal, which is transferred by the transducer cable to the data logger and then saved as a measured value. A rugged servo potentiometer is used in the shaft encoder for measuring the runoff water level with a least count of $1 \mathrm{~mm}$. The pulley drives a servo potentiometer. The unit reads the signal from the servopotentiometer, converts it to measured "runoff water level" in $\mathrm{mm}$. A real time clock has been built in it, which keeps the time of the day and provides time of measurement of runoff water levels. Every two seconds, IDRSMU measures the runoff water levels and then it calculates the average of 30 such runoff water level readings in one minute. When the average runoff water level exceeds the "set_record_runoff_min" set in the system, it stores this runoff water level in its 2 MB flash memory along with date and time. This process continues until the runoff water level falls below the "set_record_runoff_min". About 260,000 such records can be stored in $2 \mathrm{MB}$ flash memory. The value of the "set_recor d_runoff_min" can be set using key board.

\subsubsection{Runoff sampling for soil loss}

The microprocessor-based IDRSMU collects the runoff samples at specified time intervals, which are analyzed in the laboratory to estimate the sediment load/sediment concentration (Fig. 5). Under idle condition, the entire system draws a very low current of about $60 \mathrm{~mA}$. The uninterrupted program in the DLCMCU enables it to keep scanning for the runoff water level in the drain/channel. The DLCMCU unit following initialization by the set runoff water level, operates the system, first by purging the pipe to clean off the old runoff water sample. The complete sequence of runoff sampling for soil loss monitoring has following steps:

Step 1: The sampling pump is switched on for "pumping - time - setting" (this can be set based on the pump discharge capacity and volume of water that needs to purge). After pumping the runoff water, for "pumping - time - setting" the pump is switched off by the DLCMCU unit.

Step 2: The motor driving the sampler nozzle arm is switched on. The motor keeps running until the limit switch gives feedback signal to the DLCMCU unit that the nozzle arm has moved by one-step forward. At this stage, the motor is automatically switched off.

Step 3: Again the runoff sampling pump is switched on for "pumping - time - setting" (this can be set based on the pump capacity and size of bottles). After filling the sampling bottle, the pump is switched off.

Step 4: The motor driving sampler nozzle arm is switched on and it keeps running until the limit switch gives feedback signal to the DLCMCU unit that the nozzle arm has moved by one-step forward. Then the motor is switched off. The sediment samples are collected with the "sample number" along with date and time.

The DLCMCU unit keeps track of sampling timing and its number. Next, runoff sample is taken again after a time "set - sampling - time - gap" elapses. In one go, the sampling unit can collect maximum 50 samples. Once sampling number reaches 51 , sampling is automatically stopped. At this stage, all the sample bottles needs to be replaced with fresh empty bottles and the sample number should be reset to 1 by using key board of DLCMCU unit.

\subsubsection{Major components of IDRSMU and their functions}

The major components of IDRSMU consist of data logger cum microprocessor control unit, shaft encoder with pulley, float, counter weight, battery charger for $6 \mathrm{~V}, 4 \mathrm{Ah}$ emergency battery, circu- 


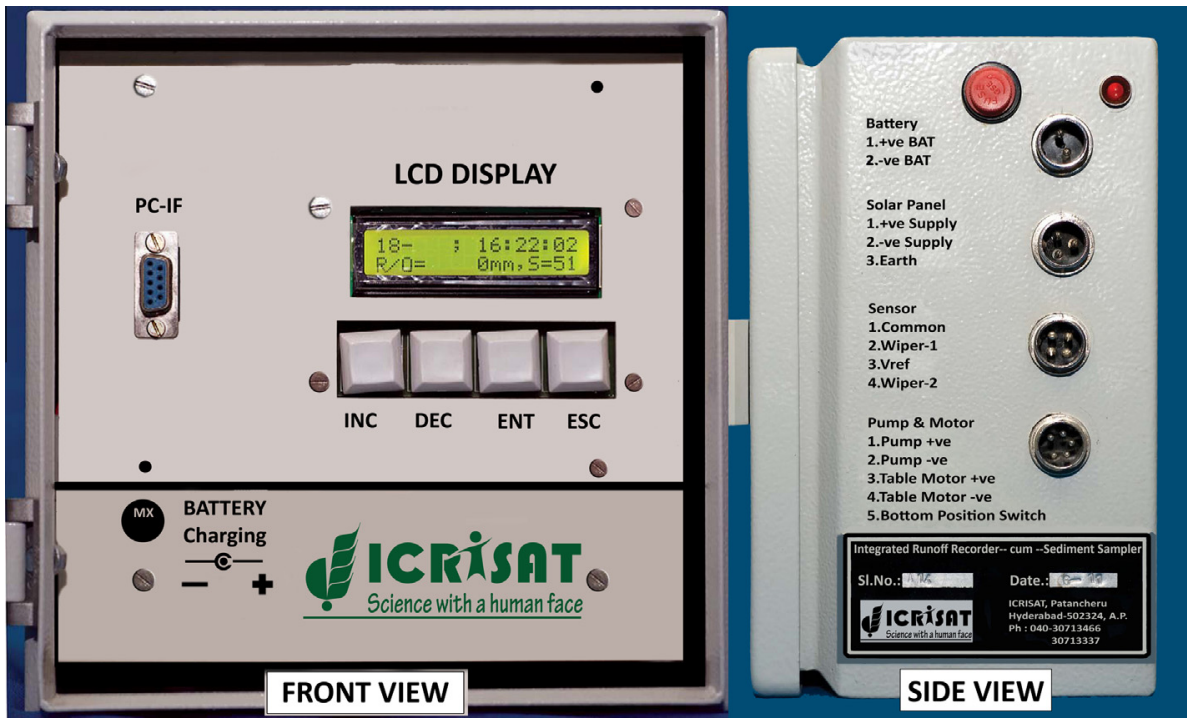

Fig. 4. Front and side view of data logger cum microprocessor control unit of IDRSMU.

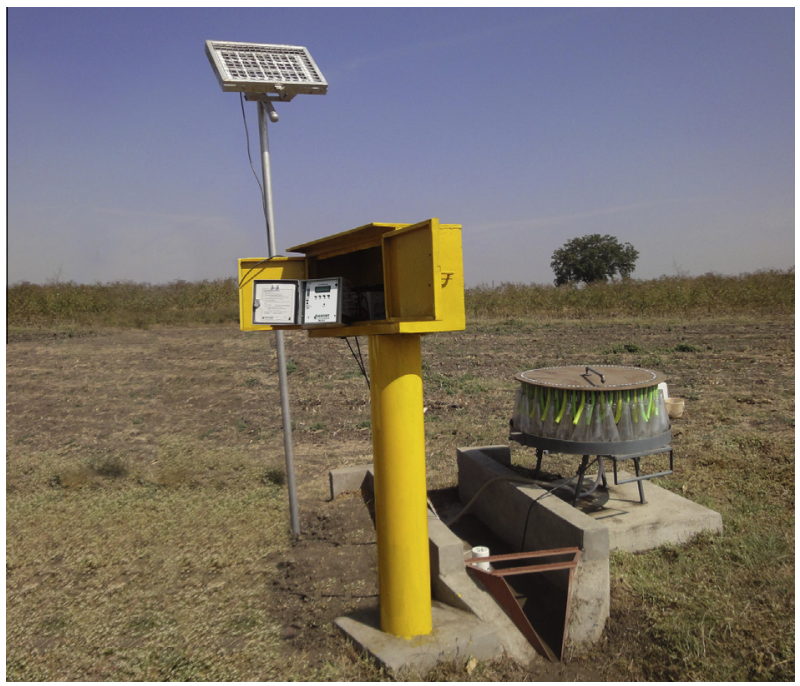

Fig. 5. Integrated runoff and soil loss monitoring unit installed at a small agricultural watershed site at the ICRISAT research center, Patancheru, India.

lar sample collection unit (50 bottles fitted with windscreen wiper motor), bilge submergible pump (discharge capacity $3550 \mathrm{l} / \mathrm{h}$ at $1 \mathrm{~m}$ head), power supply $12 \mathrm{~V}, 55 \mathrm{Ah}$ main battery and $6 \mathrm{~V}, 4 \mathrm{Ah}$ emergency battery and solar panel (for recharging battery).

The DLCMCU unit is the most important component of the IDRSMU. This unit controls the operations of all other components/parts. It records as well as stores the runoff and other associated relevant data. The electronic circuit diagram of the main PC board of DLCMCU unit is shown in Fig. 6. A crystal controlled real time clock is built in the electronic circuit of DLCMCU unit. This provides date and time of recording data. Date and time can be set through DLCMCU key board or through PC interface.

Through DLCMCU various parameters can be seen and set through a " $2 \times 16$ character backlit alphanumeric LCD display" and "4 keys key-pad" (Fig. 4). Total 12 menus are available in DLCMCU unit, which allow viewing and setting various operational parameters viz. date \& time, water level, next sample bottle number, voltage status of main and emergency batteries and setting of its limits for power charge controller, to see the stored data, to reset the sample bottle number to 1 whenever necessary, setting "set_record_runoff_minimum”, setting “set_sampling_runoff_mini mun", setting "set_sampling_time gap", setting "set_pumping_ time", setting "mm per_10 revolutions", and switching on/off of PC-interface port.

A provision has been given to download the data stored in $2 \mathrm{MB}$ flash RAM into PC via 9-pin female D-connector (RS232C) located adjacent to the LCD display. Through PC- interface several operations viz. setting date and time, erasing existing records, entering location name, downloading records into PC, and switching OFF the PC-interface after completion of job.

The IDRSMU unit has been designed to be power efficient. It consumes very small power as it goes into "sleep" mode most of the time. It senses every $5 \mathrm{~s}$, and performs all the operations necessary and again goes into "sleep" mode. The emergency battery in the DLCMCU unit keeps the runoff recorder running. It consumes only about $0.7 \mathrm{~mA}$ power during normal operation. A fully charged emergency battery can record runoff for about 6 months.

The layout and electrical wiring of different components of IDRSMU is shown in Fig. 7. The relative positions of different components can be adjusted as per the availability of space at the monitoring site.

\subsubsection{Field-testing of integrated runoff and soil loss monitoring unit}

Intensive testing and evaluation under field conditions was carried out to determine the IDRSMU sampler efficiency and accuracy at various runoff and sediment flow conditions. During 2010 and 2011 seasons, the testing was done on two small agricultural watersheds one on an Alfisol and another on Vertic Inceptisol. At each watershed, two types of samplers viz. IDRSMU and microprocessor based standard sediment sampler were used for collecting runoff samples for the soil loss estimation. In the standard sediment sampler, a more frequent runoff sampling interval of 10 min was used while in the IDRSMU sampler the runoff sampling intervals varied between 5 and $20 \mathrm{~min}$ which automatically changed as per the runoff flow height. Higher the runoff flow more frequent runoff samples were collected by the IDRSMU sampler. Good agreement can be seen (Figs. 8 and 9) between the soil loss measured by microprocessor based standard sampler and IDRSMU sampler on both the Alfisol and Vertic Inceptisol watersheds. However, between the two soils slightly better agreement was observed on the Alfisols with coarse soil particles. This could be 


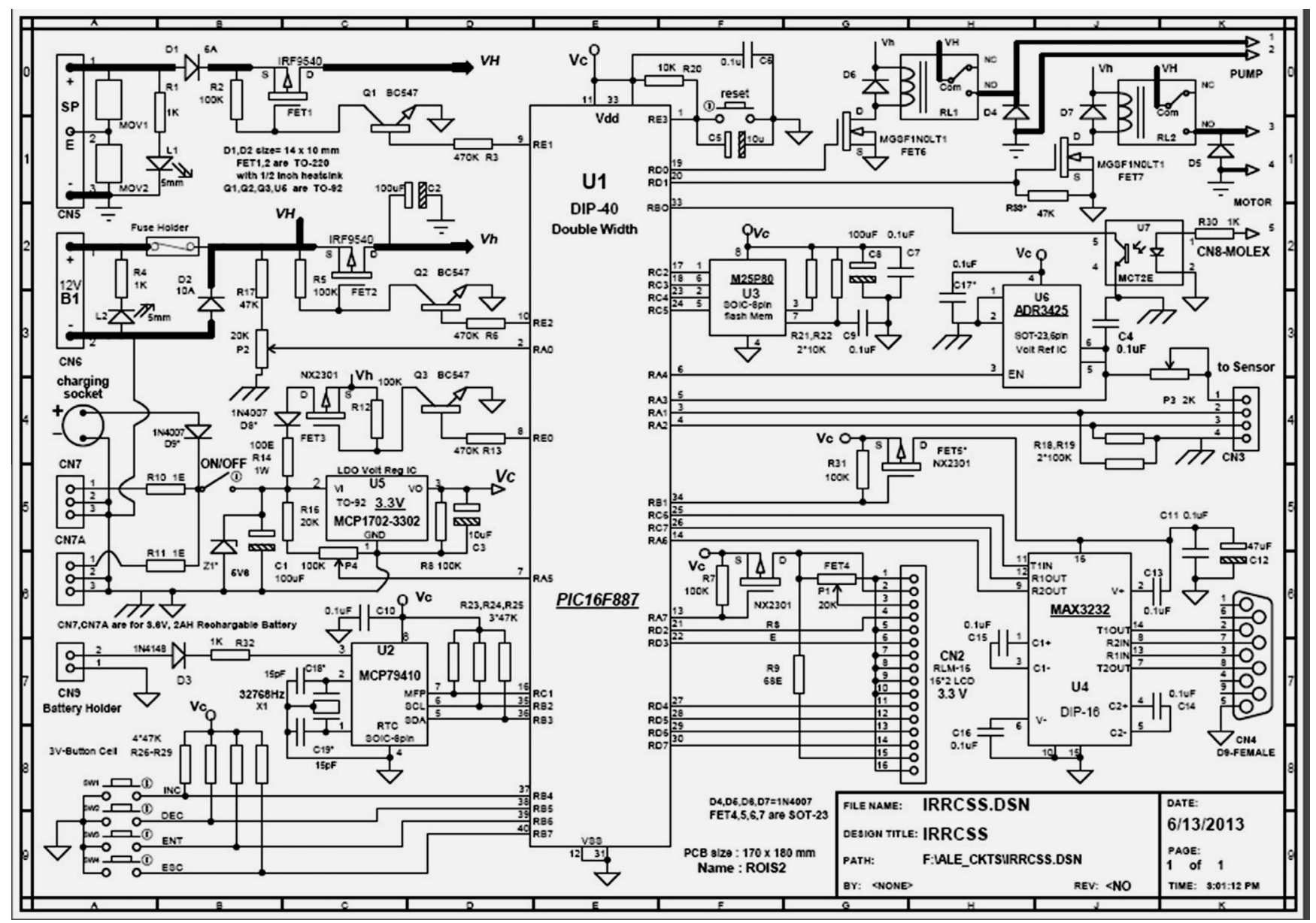

Fig. 6. The circuit diagram of DLCMCU main PC board.

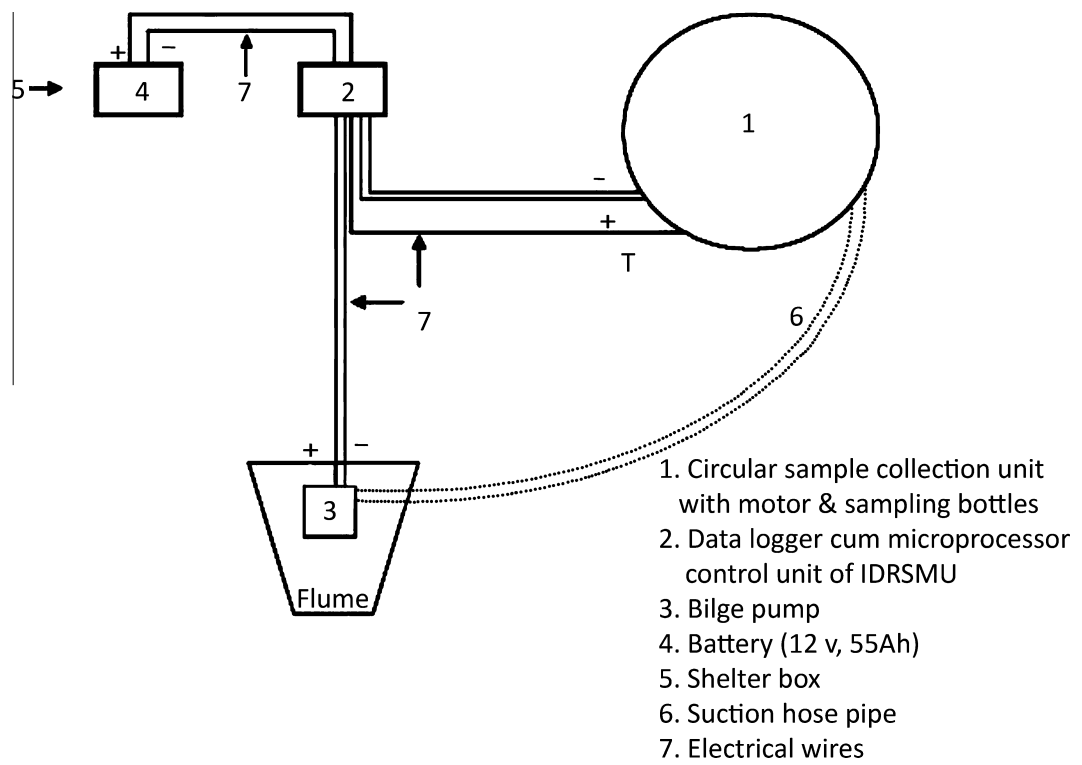

Fig. 7. Layout and electrical wiring of different parts/components of IDRSMU.

primarily because on the Alfisol, a better response to runoff discharge rate vs. sediment concentration was recorded (Fig. 2). Under such situations, IDRSMU sampler is expected to perform better than other type of sediment samplers. Its overall accuracy in monitoring soil loss is found in range 95-99\% when compared with a standard microprocessor based sediment sampler. The eroded sediment catching efficiency is recorded as high as $99.5 \%$ for finer clay particles, while for coarse sand particles it is as low 


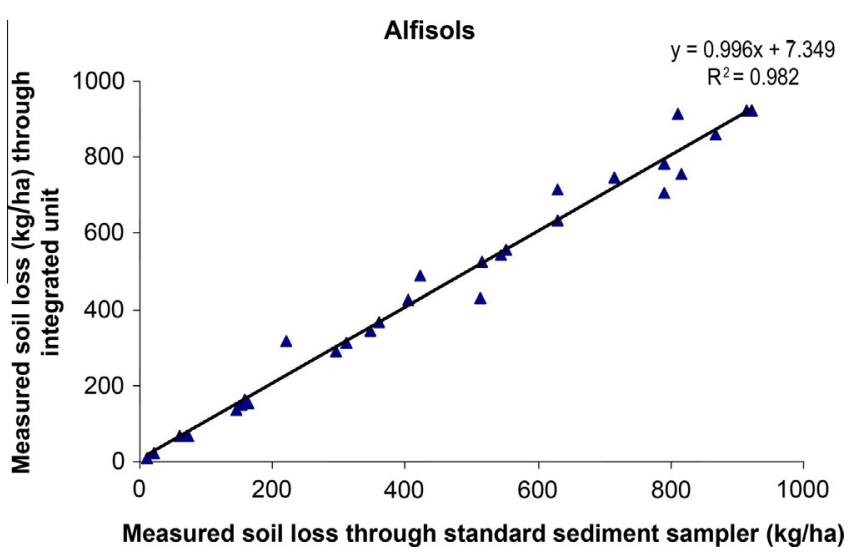

Fig. 8. Comparison of measured soil loss by integrated runoff and soil loss monitoring unit and microprocessor based standard sediment sampler in an Alfisol watershed during 2010-2012.

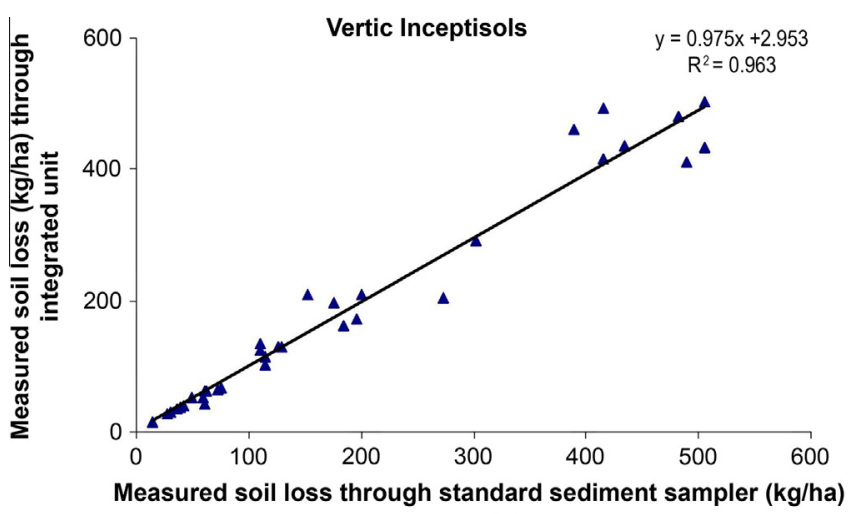

Fig. 9. Comparison of measured soil loss by integrated runoff and soil loss monitoring unit and microprocessor based standard sediment sampler in a Vertic Inceptisols watershed during 2010-2012.

as $91 \%$. One of the most significant advantages which was observed, was that in IDRSMU sampler about 30-50\% less number of runoff samples were collected depending upon the individual runoff event flow characteristics. This means that with IDRSMU sampler we need to collect, transport and analyze significantly less numbers of runoff samples. In soil loss monitoring, the analysis of the runoff samples in laboratory is the major costs. Therefore, the IDRSMU system of soil loss monitoring saves considerable operational costs along with other advantages and this is without compromising on the accuracy of soil loss estimation. This is only possible in the integrated runoff and soil loss monitoring system such as IDRSMU which can do smart runoff sampling by linking the runoff sampling interval with the sediment load flow characteristics.

Currently there are more than 105 IDRSMU units, which are being used by various research and developmental organizations in India. It is also currently used in Ethiopia, Thailand and China for monitoring runoff and soil loss from the small agricultural watersheds. The overall performance reported by these organizations has been quite good.

\subsubsection{Cost of IDRSMU and scope for mass production}

The design and development of IDRSMU took about 10 months. Initially two prototypes of IDRSMU were made which were tested both under laboratory and field conditions for about one year. Based on the feedback from laboratory and field testing's, changes were made and final version of IDRSMU was developed. So the total time taken from initial stage to final IDRSMU was about one year and ten months. The cost of one IDRSMU unit along with its accessories is US\$ 610 (Indian Rs. 41,000/-). During last few years the demand of IDRSMU has been growing. There is good potential to go for mass production in partnership with some private company. Currently large numbers of agricultural watershed programs are going on in south-east Asian and African countries. The developed integrated IDRSMU could be used for monitoring runoff and soil loss from such watershed programs.

\subsubsection{Salient features of IDRSMU}

- It can be used for monitoring both runoff and soil loss.

- It is low-cost yet efficient and accurate equipment especially for small agricultural watersheds.

- It has programmable setting of runoff sampling, data logging intervals and other parameters.

- It has good data storage capacity (up to 260,000 measured values can be stored).

- Since it is integrated runoff and soil loss monitoring unit, this makes the estimation of soil loss easy, fast as well as accurate.

- It allows browsing of all the stored data through LCD display and key board. Thus having a PC or laptop is not necessary to have a glance at the stored data.

- The biggest advantage of the unit is that it can do smart runoff sampling leading considerable cost savings in runoff sample collection and it laboratory analysis.

\section{Conclusion}

During the runoff event, high variation in sediment concentration has been recorded from small agricultural watersheds. Results indicated a positive relationship between the runoff discharge rate and sediment concentration. It has been found that a small part of runoff hydrograph usually accounted for about $65-85 \%$ of the total storm soil loss. The sediment flow behavior from small agricultural watersheds suggests the need for an integrated runoff and soil loss monitoring unit, which should be capable of doing smart runoff sampling, based on runoff discharge rate and sediment load condition. The developed integrated digital runoff and soil loss monitoring unit can be effectively used for monitoring the runoff and soil loss from small agricultural watersheds. Its accuracy in monitoring soil loss is found in range 95-99\% when compared with a standard microprocessor based sediment sampler. The eroded sediment catching efficiency of this unit is recorded as high as $99.5 \%$ for finer clay particles, while for coarse sand particles it is as low as $91 \%$. Its overall performance has been found quite well both in terms of monitoring runoff and soil loss. It is cost effective and since it is an integrated runoff and soil loss monitoring unit, this makes the estimation of soil loss easy, fast and accurate. It can do the smart runoff sampling by linking the runoff sampling interval to discharge rate/sediment load, thus making it more effective and efficient. Its biggest advantage is reduced operational costs (less runoff samples reduce the collection, transportation and laboratory analysis costs) without compromising on the accuracy and efficiency of soil loss estimation.

\section{Acknowledgements}

The authors are thankful to Dr. K.L. Sahrawat, and Dr. Piara Singh, Consultant, ICRISAT, for their comments and suggestions on the paper. We also acknowledge the contribution of Mr. L.J. Naidu, Senior Scientific Associate, ICRISAT Development Center, ICRISAT, in collecting the data from the experiments. 


\section{References}

Black, T.A., Luce, C.H., 2013. Measuring Water and Sediment Discharge from a Road Plot with a Settling Basin and Tipping Bucket Gen. Tech. Rep. RMRS-GTR-287. U.S. Department of Agriculture, Forest Service, Rocky Mountain Research Station, Fort Collins, CO, p. 38.

Davis, B.E., 2005. A Guide to the Proper Selection and Use of Federally Approved Sediment and Water-quality Samplers (No. 2005-1087). US Geological Society.

Dendy, F.E., 1973. Traversing-Slot Runoff Sampler for Small Watersheds. Agricultural Research Service, United States.

Douglas, L.H., 2001. A summary of techniques for measuring soil erosion. Environmental performance indicators Technical Paper No. 69 "Land". NZ Ministry for the Environment and Regional Councils, Land Monitoring Group.

Eads, R.E., Boolootian, M.R., 1985. Controlling Suspended Sediment Samplers by Programmable Calculator and Interface Circuitry, vol. 376. US Dept. of Agriculture, Forest Service, Pacific Southwest Forest and Range Experiment Station.

El-Swaify, S.A., Pathak, P., Rego, T.J., Singh, S., 1985. Soil management for optimized productivity under rainfed conditions in the semi-arid tropics. Adv. Soil Sci. 1, 1-64. http://dx.doi.org/10.1007/978-1-4612-5046-3_1.

Fasinmirin, J.T., 2009. Development and calibration of a digital recording system for automation of runoff measurement. J. Appl. Irrig. Sci. 44 (2), 177-185.

Klik, A., Sokol, W., Steindl, F., 2004. Automated erosion wheel: a new measuring device for field erosion plots. J. Soil Water Conserv. 59 (3), 116-121.

Kornecki, T.S., Fouss, J.L., Prior, S.A., 2008. A portable device to measure soil erosion/ deposition in quarter-drains. Soil Use Manage. 24 (4), 401-408. http://dx.doi. org/10.1111/j.1475-2743.2008.00181.x.

Pagiola, S., 1999. The Global Environmental Benefits of Land Degradation Control on Agricultural Land: Global Overlays Program. World Bank Publications, p. 16.
Pathak, P., 1991. Runoff sampler for small agricultural watersheds. Agric. Water Manage. 19 (2), 105-115. http://dx.doi.org/10.1016/0378-3774(91)90002-Z.

Pathak, P., Wani, S.P., Singh, P., Sudi, R., 2004. Sediment flow behaviour from small agricultural watersheds. Agric. Water Manage. 67 (2), 105-117. http://dx.doi. org $/ 10.1016 / j$.agwat.2004.02.005.

Pathak, P., Sudi, R., Wani, S.P., Sahrawat, K.L., 2013. Hydrological behavior of Alfisols and Vertisols in the semi-arid zone: implications for soil and water management. Agric. Water Manage. 118, 12-21. http://dx.doi.org/10.1016/j. agwat.2012.11.012.

Polyakov, V.O., Nearing, M.A., Hawdon, A.A., Wilkinson, S.N., Nichols, M.H., 2013. Comparison of two stream gauging systems for measuring runoff and sediment yield for a semi-arid watershed. Earth Surf. Process. Landforms 38 (4), 383-390. http://dx.doi.org/10.1002/esp.3287.

Sun, T., Cruse, R.M., Chen, Q., Li, H., Song, C., Zhang, X., 2014. Design and initial evaluation of a portable in situ runoff and sediment monitoring device. J. Hydrol. 519, 1141-1148. http://dx.doi.org/10.1016/j.jhydrol.2014.08.048.

Virmani, S.M., Pathak, P., Singh, R., 1991. Soil-related Constraints in Dryland Crop Production in Vertisols, Alfisols and Entisols of India. In Soil Related Constraints in Crop Production. Bulletin 15, Indian Society of Soil Science, pp. 80-95.

Wang, J.Y., Hermanson, R.E., Hendrick, J.G., 1971. Modification of H-flume and Coshocton wheel system. Trans. ASAE 14 (6), 1015-1017.

Zeng, W., Zhang, Y., Chen, L., Wang, D., Dong, X., Wang, Y., 2014. Dynamic measured system for hillslope runoff rate and sediment concentration based on time method and illumination method. Trans. Chin. Soc. Agric. Eng. 30 (24), 114-123.

Zhang, B., Gao, Y.X., Cui, H.H., 2014. A brief introduction to the measuring methods for sediment concentration of runoff and providing a new idea. Appl. Mech. Mater. 530, 141-145.

Zhao, S.L., Dorsey, E.C., Gupta, S.C., Moncrief, J.F., Huggins, D.R., 2001. Automated water sampling and flow measuring devices for runoff and subsurface drainage. J. Soil Water Conserv. 56 (4), 299-306. 